\title{
Hierarchical Ag-ZnO Microspheres with Enhanced Photocatalytic Degradation Activities
}

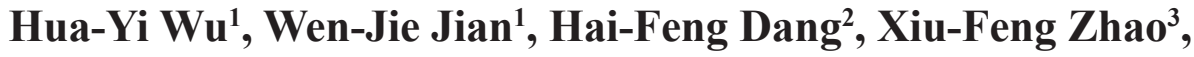 \\ Li-Zhong Zhang ${ }^{3}$, Jian-Hui Li $^{3,4 *}$
}

\begin{abstract}
${ }^{1}$ Department of pharmacy, Xiamen Medical College, Xiamen 361008, China
${ }^{2}$ College of Chemistry and Environmental Engineering, Guangdong Engineering and Technology Research Center for Advanced Nanomaterials, Dongguan University of Technology, Dongguan 523808, China

${ }^{3}$ Department of Chemistry and Applied Chemistry, Changji University, Changji 831100, China ${ }^{4}$ State Key Laboratory of Physical Chemistry of Solid Surfaces, National Engineering Laboratory for Green Chemical Productions of Alcohols, Ethers and Esters, and Department of Chemistry, College of Chemistry and Chemical Engineering, Xiamen University, Xiamen 361005, China
\end{abstract}

Received: 26 July 2016

Accepted: 26 September 2016

\begin{abstract}
In this work, the significantly enhanced photocatalytic performances and higher reaction rate of the hierarchical $\mathrm{ZnO}$ microspheres - initially prepared by a solvothermal method without surfactants or templates and decorated with Ag nanoparticles by a photoreduction method - were found for the degradation of methylene blue (MB) under both ultraviolet (UV) and visible light irradiation. Various characterization results confirmed that the modification of silver with an optimal amount can effectively extend the absorption spectrum to the visible region and inhibit a recombination of photo-induced charge carriers. Moreover, the reason for promoted photostability and the possible mechanism for the enhanced photocatalytic activity of the as-prepared $\mathrm{Ag} / \mathrm{ZnO}$ composites under $\mathrm{UV}$ or visible light irradiation were also systematically investigated and discussed.
\end{abstract}

Keywords: hierarchical, photodegradation, visible light, $\mathrm{Ag} / \mathrm{ZnO}$ composites, microspheres

\section{Introduction}

Recently, as a potential solution handling environmental pollutants, photo-catalysis using an effective semiconductor has been a research focus,

*e-mail: jhli@xmu.edu.cn particularly for the elimination of hazardous materials in polluted water [1-2]. Among various semiconductors, $\mathrm{ZnO}$ has been considered as an excellent photocatalyst candidate with respect to its high photosensitivity, non-toxicity, abundant availability, low cost, etc. [3-4]. However, the practical application of unitary $\mathrm{ZnO}$ materials still confronts two challenges, i.e., the limited absorption spectrum range within UV light $(\lambda<387 \mathrm{~nm})$ [5] and severe recombination of 
photogenerated electron-hole pairs resulting in relatively low quantum yields [6].

So far, diverse strategies have been explored to overcome the aforementioned drawbacks, including surface alteration [7], formation of heterostructures [8-10] or nanocomposites [11-12] modified with polymer [13] or metals [14-15], etc. Many researchers have demonstrated a significantly extended light-absorption range and prolonging the lifetimes of photoexcited charge carriers through the decoration of noble metal nanoparticles onto $\mathrm{ZnO}$ [16-19]. This is mainly due to the respective effects of surface plasmon resonance (SPR) and the formation of a Schottky barrier at the metal-ZnO interface. Among the noble metals investigated, nano Ag plays a crucial role in the enhancement of photocatalytic performance for the degradation of organic dyes $[17,20]$.

The nanostructured semiconductor has attracted increasing attention as one of the promising photocatalysts for its large surface area and large number of active sites. However, nanosized materials with high surfaceto-volume ratios suffer significantly from aggregation, deactivation, and recyclability in aqueous photocatalytic reactions. Compared with powder-like nanoparticles, photocatalysts with hierarchical microsphere structure could present superior performance in the photocatalytic reaction because of their low density, high surface area, easy settlement, good delivering ability, and surface permeability [21-25].

Ag-ZnO composites are usually synthesized using the "one-pot" method by co-heat-treatment of mixed Ag and $\mathrm{Zn}$ precursor at high temperature [26-27] which, however, suffers from the restrictions of the time-consuming process and uncontrolled Ag particle sizes. It has been reported that the silver ion can be reduced to metallic Ag and deposited onto the substrate surface by the photogenerated electron in the solution - the so-called photoreduction method [28-29], which is proved to be simple, efficient, and lowcost. Furthermore, as mentioned above, the assembled hierarchical microsphere structures for modified $\mathrm{ZnO}$ have an overall dimension in micrometers and are stable enough to resist agglomeration. The photocatalytic activities of the assembled structures will be maintained for the existence of nanosized catalytic active units or even higher, since more lights scattered over the hierarchical microsphere structure will lead to better light adsorption. Therefore, decorated Ag nanoparticles on the surface of $\mathrm{ZnO}$ microspheres forming a hierarchical photocatalyst using the simple photoreduction method is an important and interesting area of research.

Herein, the catalytic active Ag-modified $\mathrm{ZnO}$ hierarchical microspheres with enhanced stability were successfully synthesized. The $\mathrm{ZnO}$ substrate selfassembled of $\mathrm{ZnO}$ nanoparticles was prepared via a facile and template-free approach. The Ag particles were decorated onto the $\mathrm{ZnO}$ surfaces by photoreduction of Ag ions. The photocatalytic activity and stability were tested with and applied to the degradation of methylene blue (MB) as a probe reaction. The possible mechanism for the desirable photocatalytic activity of $\mathrm{Ag} / \mathrm{ZnO}$ composites under UV or visible light irradiation was also proposed.

\section{Materials and Method}

\section{Synthesis of Hierarchical ZnO Microspheres}

Typically, $0.48 \mathrm{mmol}$ zinc nitrate hexahydrate $\left(\mathrm{Zn}\left(\mathrm{NO}_{3}\right)_{2} \cdot 6 \mathrm{H}_{2} \mathrm{O}\right), 0.26 \mathrm{mmol}$ methenamine $\left(\left(\mathrm{CH}_{2}\right)_{6} \mathrm{~N}_{4}\right)$, and $0.06 \mathrm{mmol}$ trisodium citrate $\left(\mathrm{C}_{6} \mathrm{H}_{5} \mathrm{Na}_{3} \mathrm{O}_{7} \cdot 2 \mathrm{H}_{2} \mathrm{O}\right)$ were dissolved in $50 \mathrm{~mL}$ distilled water. After being sonicated for $5 \mathrm{~min}$, the mixture was then heated at $90^{\circ} \mathrm{C}$ for $2 \mathrm{~h}$ and then aged at ambient temperature for $10 \mathrm{~h}$. The resulting precipitates were obtained by centrifugation, washed with ethanol and deionized water, and then dried at $60^{\circ} \mathrm{C}$ for $10 \mathrm{~h}$. Subsequently, the final hierarchical $\mathrm{ZnO}$ microspheres were achieved through a heat treatment of the precursors at $450^{\circ} \mathrm{C}$ in air for $30 \mathrm{~min}$.

\section{Synthesis of Ag-Modified ZnO Microspheres}

For the preparation of Ag-modified $\mathrm{ZnO}$ microspheres (denoted as $\mathrm{Ag} / \mathrm{ZnO}$ ), $0.2 \mathrm{~g}$ of the synthesized $\mathrm{ZnO}$ microspheres was dispersed into $100 \mathrm{~mL}$ distilled water by sonication for $20 \mathrm{~min}$, followed by the addition of different amounts of $\mathrm{AgNO}_{3}$. The above suspension was stirred in the dark for $0.5 \mathrm{~h}$ and then irradiated for $0.5 \mathrm{~h}$ by employing a high-pressure Hg UV lamp. Then the mixture was centrifuged and washed with distilled water and alcohol several times. The products were dried at $60^{\circ} \mathrm{C}$ for $12 \mathrm{~h}$. The precise $\mathrm{Ag}$ contents of the $\mathrm{Ag} / \mathrm{ZnO}$ composites were determined by the AAS analysis and the results are listed in Table 1. Therefore, the $\mathrm{Ag} / \mathrm{ZnO}$ composites prepared with different $\mathrm{AgNO}_{3}$ concentrations of $0.3 \mathrm{mmol}, 0.6 \mathrm{mmol}, 1.2 \mathrm{mmol}$, and $2.4 \mathrm{mmol}$ are hereafter denoted as $5.41 \quad \mathrm{wt} \% \mathrm{Ag} / \mathrm{ZnO}, 7.95 \mathrm{wt} \%$ $\mathrm{Ag} / \mathrm{ZnO}, 10.03 \mathrm{wt} \% \mathrm{Ag} / \mathrm{ZnO}$, and $11.37 \mathrm{wt} \% \mathrm{Ag} / \mathrm{ZnO}$, respectively.

\section{Characterization}

X-ray diffraction (XRD) measurement was carried out by a RigakuUltima IV x-ray diffractometer with $\mathrm{Cu}-\mathrm{Ka}$ radiation $(\lambda=0.15418 \mathrm{~nm})$ for phase identification. The morphologies of the products were investigated by a Hitachi S-4800 field-emission scanning electron microscope (SEM) and TECNAI F-30 FEG transmission

Table 1. The Ag contents in various $\mathrm{Ag} / \mathrm{ZnO}$ samples.

\begin{tabular}{|c|c|c|c|}
\hline Sample & $\begin{array}{c}\mathrm{AgNO}_{3} / \\
\mathrm{mmol}\end{array}$ & $\begin{array}{c}\text { Irradiation } \\
\text { time / min }\end{array}$ & $\mathrm{Ag} / \mathrm{wt} \%$ \\
\hline 1 & 0.3 & 30 & 5.41 \\
\hline 2 & 0.6 & 30 & 7.95 \\
\hline 3 & 1.2 & 30 & 10.03 \\
\hline 4 & 2.4 & 30 & 11.37 \\
\hline
\end{tabular}


electron microscope (TEM). Chemical compositions were measured by x-ray energy-dispersive spectroscopy (EDS) equipped with TEM. The silver contents in the Ag/ZnO composites were quantified by a Shimadzu Model AA670 flame atomic absorption spectrometer. $\mathrm{N}_{2}$ adsorption/ desorption isotherms were recorded at $77 \mathrm{~K}$ on an automated micromeritics Tri-Star 3000 apparatus. Surface areas were calculated using the multipoint BET equation. Fourier transforms infrared spectrometer (FT-IR) spectra were recorded in $\mathrm{KBr}$ dispersion in the range of 400 to $4,000 \mathrm{~cm}^{-1}$. The surface compositions of the samples were obtained from x-ray photoelectron spectroscopy (XPS) using a VG ESCALAB/Auger. UV/vis absorption spectra were recorded with a UV-vis spectrophotometer (Cary $5000)$ with an integrating sphere attachment and $\mathrm{BaSO}_{4}$ as a reflectance standard. The photoluminescence (PL) spectra were measured on a Hitachi F-7000 luminescence spectrometer at room temperature.

\section{Photocatalytic Activities Test}

The photocatalytic performance of the $\mathrm{ZnO}$ and $\mathrm{Ag} / \mathrm{ZnO}$ samples were evaluated by examining the degradation of methylene blue (MB) chosen as model chemical. A high-pressure Hg UV lamp $(250 \mathrm{~W})$ with a maximum emission at $365 \mathrm{~nm}$ served as the UV resource for UV light photocatalysis. A $500 \mathrm{~W}$ Xenon lamp with a filter $(420 \mathrm{~nm})$ to cut off the UV light was used as the visible light source. Typically, $20 \mathrm{mg}$ of the catalysts $(\mathrm{Ag} / \mathrm{ZnO}$ or $\mathrm{ZnO})$ were ultrasonically dispersed into $40 \mathrm{~mL}$ aqueous suspensions of MB (10 mg/L). Prior to irradiation, the mixture was stirred in the dark for $30 \mathrm{~min}$ to establish an adsorption/desorption equilibrium. After a given irradiation time, a certain amount of solutions was collected and centrifuged to remove the photocatalysts. Subsequently, the residual MB concentration was tested by a UV-vis spectrophotometer.

\section{Results and Discussion}

XRD patterns of $\mathrm{ZnO}$ and $\mathrm{Ag} / \mathrm{ZnO}$ microspheres with different $\mathrm{Ag}$ content are shown in Fig. 1. All the diffraction peaks in Fig. 1a) can be perfectly assigned to wurtzite-structured $\mathrm{ZnO}$ (JCPDS NO. 36-1451). As shown in Figs. 1b-e), two sets of diffraction peaks existed for all the Ag-modified samples, which were attributed to the wurtzite-structured $\mathrm{ZnO}$ and face-centered cubic sliver (JCPDS NO. 04-0783) [30-32]. The diffraction peaks of $\mathrm{Ag}$ were strengthened gradually when the Ag content in the composites increased from 5.41 to $11.37 \mathrm{wt} \%$. No additional peaks for impurity were detected, suggesting that the $\mathrm{Ag} / \mathrm{ZnO}$ composites were composed of $\mathrm{Ag}$ and $\mathrm{ZnO}$.

Fig. 2 shows the SEM and TEM images of as-prepared $\mathrm{ZnO}$ and $\mathrm{Ag} / \mathrm{ZnO}$ composites. As shown in Fig. 2a), the $\mathrm{ZnO}$ samples mainly consist of hierarchical microspheres with an average size of approximately $2 \mu \mathrm{m}$. The highly magnified SEM image of a fragment of the sphere

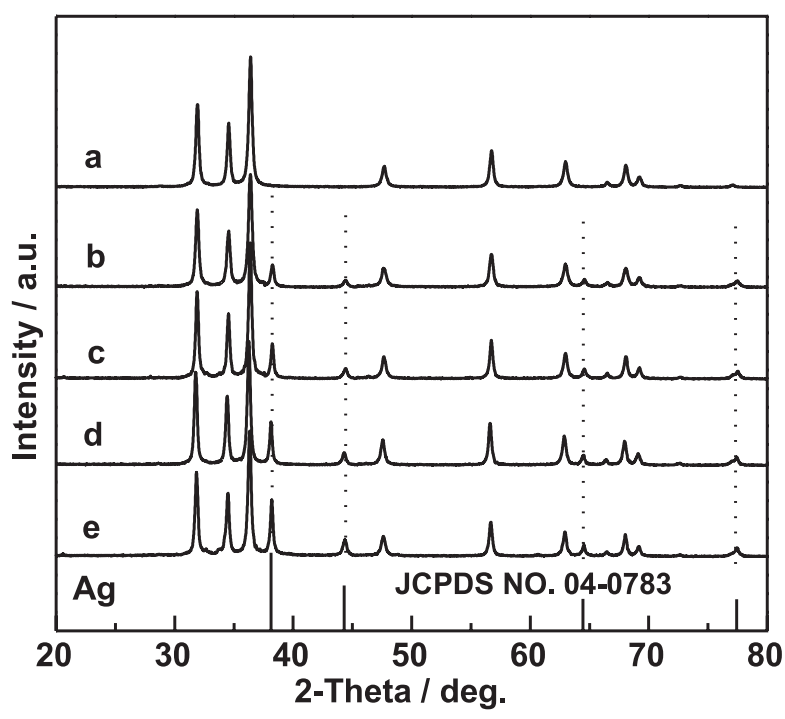

Fig. 1. The XRD patterns of a) $\mathrm{ZnO}$, b) $5.41 \mathrm{wt} \% \mathrm{Ag} / \mathrm{ZnO}$, c) $7.95 \mathrm{wt} \% \mathrm{Ag} / \mathrm{ZnO}$, d) $10.03 \mathrm{wt} \% \mathrm{Ag} / \mathrm{ZnO}$, and e) $11.37 \mathrm{wt} \%$ $\mathrm{Ag} / \mathrm{ZnO}$.

(Fig. 2b) exhibits that the architecture of the hierarchical $\mathrm{ZnO}$ microsphere are built from numerous oriented nanoparticles. A large number of pores are engendered in the microspheres, which can increase the accessible surface area of the materials and is conducive to the transport of small molecules. Figs 2 (c, d) exhibit the SEM images of
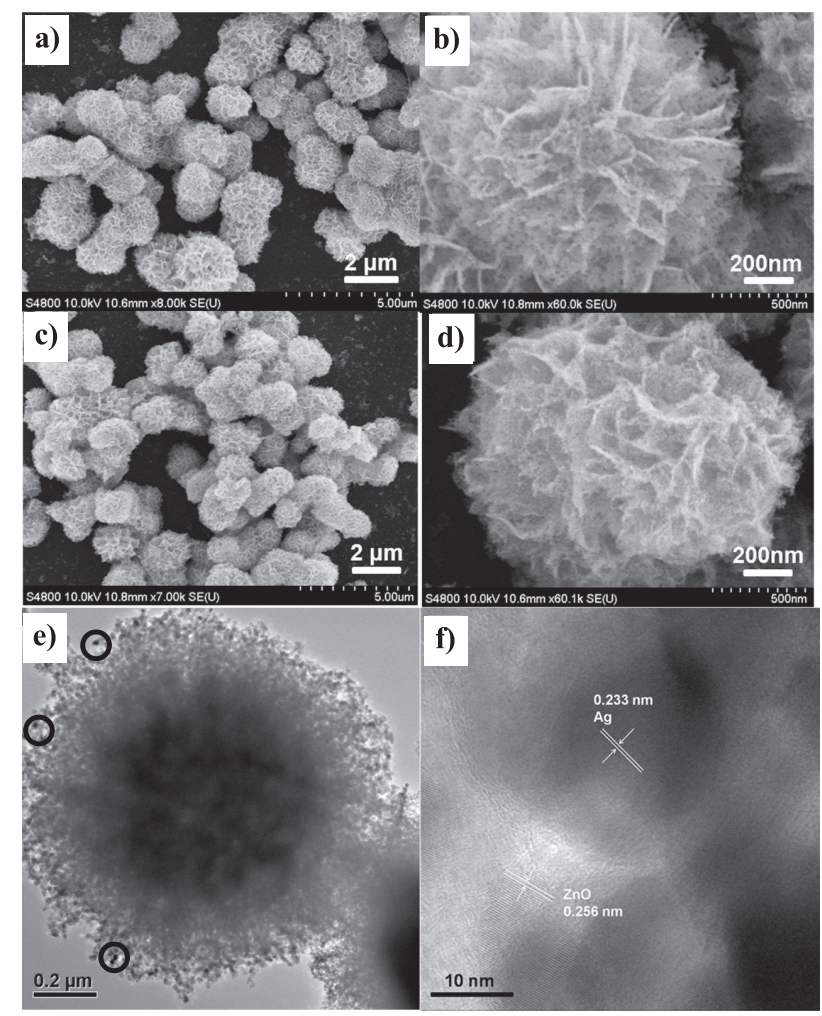

Fig. 2. The SEM images of (a, b) hierarchical $\mathrm{ZnO}$ microspheres, (c, d) $10.03 \mathrm{wt} \% \mathrm{Ag} / \mathrm{ZnO}$, e) TEM, and f) HRTEM images of $10.03 \mathrm{wt} \% \mathrm{Ag} / \mathrm{ZnO}$ samples. 


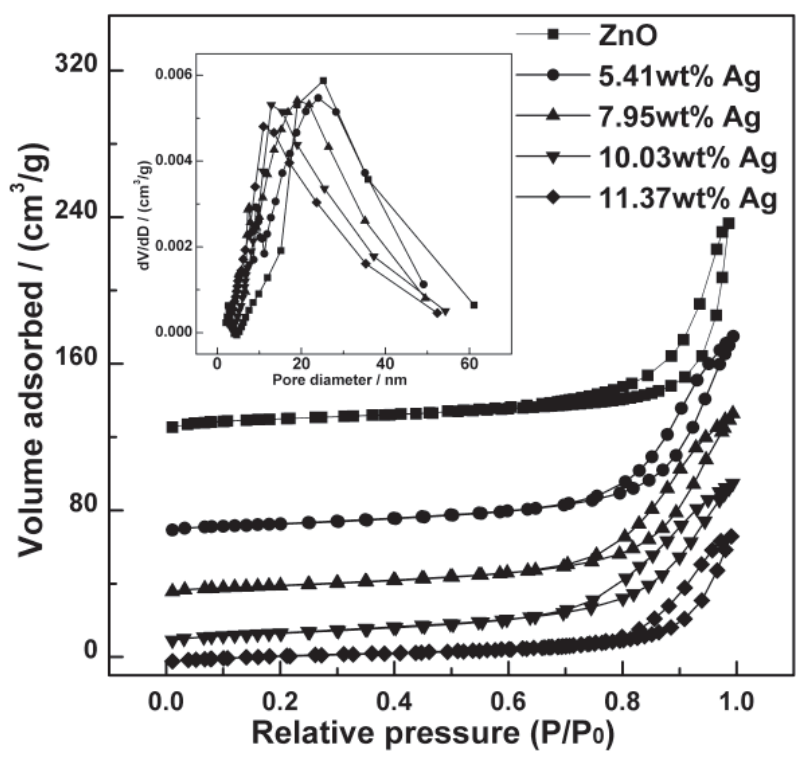

Fig. 3. $\mathrm{N}_{2}$ adsorption-desorption isotherm and $\mathrm{BJH}$ pore diameter distribution (inset) of $\mathrm{ZnO}$ - and $\mathrm{Ag}$-doped $\mathrm{ZnO}$.

$\mathrm{Ag} / \mathrm{ZnO}$ composites. It is clear that the morphology of $\mathrm{ZnO}$ remains unchanged after Ag modification. The TEM image, as shown in Fig. 2e), further confirms the results obtained from SEM observations. The original structure is well inherited by the $\mathrm{Ag} / \mathrm{ZnO}$ microspheres, and numerous nanopores can also be observed. In addition, many
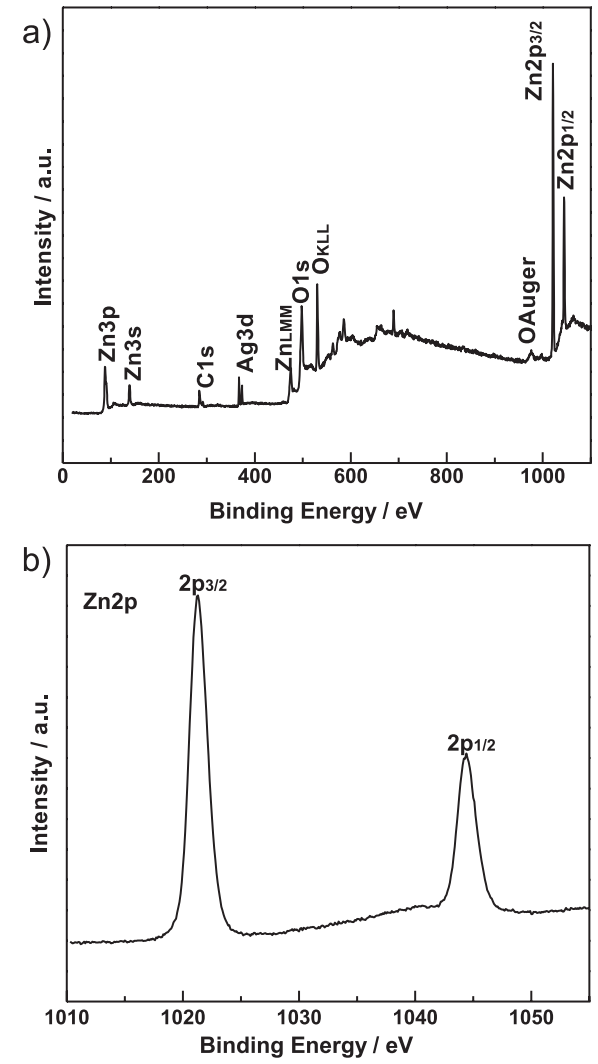

spherical Ag nanoparticles appear on the surface of the $\mathrm{ZnO}$ microsphere. To achieve more convincible evidence, the HRTEM image of the $\mathrm{Ag} / \mathrm{ZnO}$ sample is depicted in Fig. 2f). The interplanar spacing of about $0.256 \mathrm{~nm}$ can be assigned to the (002) plane of $\mathrm{ZnO}$, while the interplanar spacing of $0.233 \mathrm{~nm}$ corresponds to the (111) plane of Ag. Energy-dispersive X-ray spectroscopy (EDS) analysis also confirms that the $\mathrm{Ag} / \mathrm{ZnO}$ composites only contain silver, zinc, and oxygen elements, which is consistent with the above-mentioned conclusion.

The nitrogen desorption/adsorption isotherms of the samples are shown in Fig. 3. The isotherms correspond to the type IV with H3-type hysteresis loop, indicating the existence of mesopores $(2-50 \mathrm{~nm})$. The inset in Fig. 3 exhibits the pore diameter distribution. It is clear that all the samples present in mesopores have diameters in the range of 2-50 $\mathrm{nm}$. All the BET surface areas of $\mathrm{ZnO}$ and Ag-modified $\mathrm{ZnO}$ are around $30 \mathrm{~m}^{2} \cdot \mathrm{g}^{-1}$, and the presence of Ag NPs does not obviously impact the BET surface area of the photocatalysts.

The chemical component of the as-obtained $10.03 \mathrm{wt} \%$ $\mathrm{Ag} / \mathrm{ZnO}$ sample was investigated by X-ray photoelectron spectroscopy (XPS) analysis and the corresponding results are shown in Fig. 4. It is clear that all of the peaks on the curve can be assigned to $\mathrm{Zn}, \mathrm{O}, \mathrm{Ag}$, and $\mathrm{C}$ elements and no peaks of other elements can be observed (Fig. $4 a)$. The existence of the $\mathrm{C}$ element could be ascribed to the hydrocarbon contaminants. The high-resolution $\mathrm{Zn} 2 \mathrm{p}$ spectrum is analyzed in Fig. $4 \mathrm{~b}$. The binding
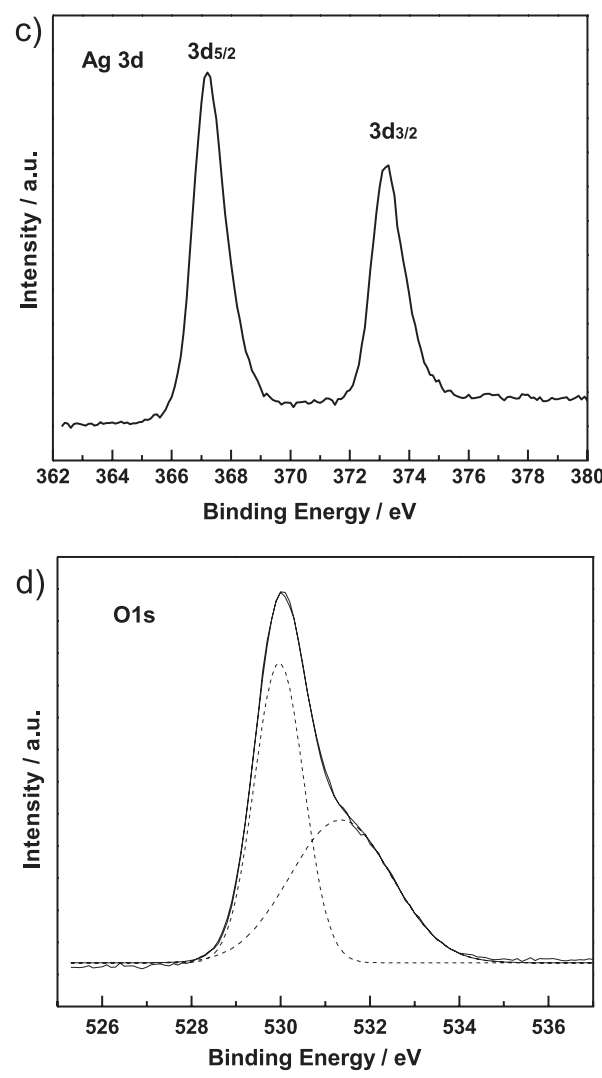

Fig. 4. Complete XPS spectra of a) $10.03 \mathrm{wt} \% \mathrm{Ag} / \mathrm{ZnO}$ sample and high-resolution spectra of sample for the elements of b) $\mathrm{Zn}, \mathrm{c}) \mathrm{Ag}$, and d) $\mathrm{O}$. 
energies of $\mathrm{Zn} 2 \mathrm{p}_{3 / 2}$ and $\mathrm{Zn} 2 \mathrm{p}_{1 / 2}$ are located at 1021.3 and $1044.4 \mathrm{eV}$, which indicates that the $\mathrm{Zn}$ element is mainly in the form of $\mathrm{Zn}^{2+}$ on the surface [33]. Fig. $4 \mathrm{c}$ displays the high-resolution $\mathrm{Ag} 3 \mathrm{~d}$ spectrum. The peak at $367.2 \mathrm{eV}$ is assigned to $\mathrm{Ag} 3 \mathrm{~d}_{5 / 2}$ and the peak at $373.2 \mathrm{eV}$ corresponds to $\mathrm{Ag} 3 \mathrm{~d}_{3 / 2}$. And the binding energies of $A g 3 d_{5 / 2}$ and $3 d_{3 / 2}$ peaks for the composites all shift to lower values compared with those of bulk silver

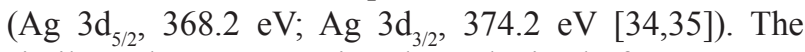
similar phenomenon is also obtained from wormlike $\mathrm{Ag} / \mathrm{ZnO}$ heterostructural composites and $\mathrm{Ag}-\mathrm{ZnO}$ heterostructural nanoparticles $[20,36]$. Such a shift is primarily due to the strong interaction between $\mathrm{Ag}$ and $\mathrm{ZnO}$. The functional work of $\mathrm{Ag}$ metallic $(4.26 \mathrm{eV})$ is lower than that of $\mathrm{ZnO}(5.3 \mathrm{eV})$, which will steer electrons from $\mathrm{Ag}$ to $\mathrm{ZnO}$ at the interfaces of $\mathrm{Ag}-\mathrm{ZnO}$ composites, leading to the higher valance of $\mathrm{Ag}$ when $\mathrm{Ag}$ nanoparticles are attached to $\mathrm{ZnO}$ microspheres. Obviously, the $\mathrm{O} 1 \mathrm{~s}$ peak exhibited in Fig. 4d is asymmetric and thus it can be deconvoluted into two symmetrical peaks. The binding energy at $531.4 \mathrm{eV}$ is associated with chemisorbed oxygen of the surface hydroxyls and the $530.1 \mathrm{eV}$ peak is associated with the lattice oxygen of $\mathrm{ZnO}$ [37].

Fig. 5 shows the UV-vis reflectance spectra of hierarchical $\mathrm{ZnO}$ microspheres and the $\mathrm{Ag} / \mathrm{ZnO}$ composites with various $\mathrm{Ag}$ contents. In the range of 200-800 nm, two absorption bands can be observed for the $\mathrm{Ag} / \mathrm{ZnO}$ composites. The absorption band located at the UV region can be ascribed to the absorption of $\mathrm{ZnO}$ and the absorption peak fell in visible range is thought to be the characteristic absorption of surface plasmon resonance (SPR) caused by silver nanoparticles [38-39]. The SPR effect tends to strengthen with the increasing of $\mathrm{Ag}$ content and can enhance the visible light absorption ability of the catalysts. Furthermore, it also means the possibility of the $\mathrm{Ag} / \mathrm{ZnO}$ composites used as a visible light-driven photocatalyst.

The PL spectrum is an effective method to characterize the optical and photochemical properties of semiconductor

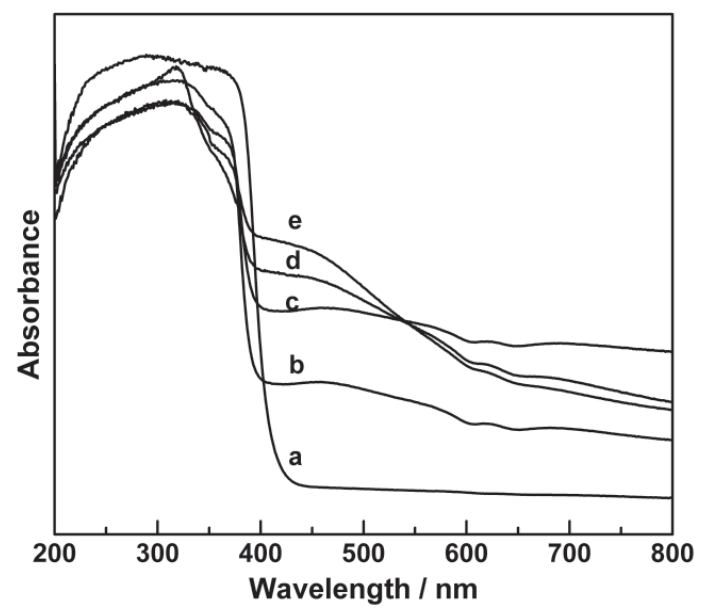

Fig. 5. UV-vis absorption spectra of a) $\mathrm{ZnO}$, b) $5.41 \mathrm{wt} \%$ $\mathrm{Ag} / \mathrm{ZnO}$, c) $7.95 \mathrm{wt} \% \mathrm{Ag} / \mathrm{ZnO}$, d) $10.03 \mathrm{wt} \% \mathrm{Ag} / \mathrm{ZnO}$, and e) $11.37 \mathrm{wt} \% \mathrm{Ag} / \mathrm{ZnO}$. materials. It can offer important information corresponding to the separation and recombination of photoinduced charge carriers of photocatalysts. Fig. 6 exhibits the roomtemperature PL spectra of the as-prepared $\mathrm{ZnO}$ and the $\mathrm{Ag} / \mathrm{ZnO}$ composites with different $\mathrm{Ag}$ contents. It is clear that the PL intensity of $\mathrm{Ag} / \mathrm{ZnO}$ composites decreases sharply in emission yield compared to pure $\mathrm{ZnO}$ - both in the UV and visible light regions. This means that the PL quenching effect occurs when $\mathrm{Ag}$ particles are introduced to the $\mathrm{ZnO}$ microspheres. The quenching effect of the $\mathrm{Ag} / \mathrm{ZnO}$ composites is arranged in the following order: $10.03 \mathrm{wt} \% \mathrm{Ag} / \mathrm{ZnO}>11.37 \mathrm{wt} \% \mathrm{Ag} / \mathrm{ZnO}>7.95 \mathrm{wt} \%$ $\mathrm{Ag} / \mathrm{ZnO}>5.41 \mathrm{wt} \% \mathrm{Ag} / \mathrm{ZnO}$. This result could be rationalized by the fact that $\mathrm{Ag}$ on the surface of $\mathrm{ZnO}$ may act as electron trappers to separate the electron-hole pairs at low loading. With increasing $\mathrm{Ag}$ content (from 5.41 to $10.03 \mathrm{wt} \%$ ), more metal sites favored to trap the electrons are formed and this leads to the enhancement in separation effects for the photoinduced electrons and holes, and thus a decrease intensity of PL emission. When the Ag content exceeds a certain amount ( $>10.03 \mathrm{wt} \%)$, an abnormal change occurs. This can be ascribed to the absorption or reflection of emission at the $\mathrm{Ag} / \mathrm{ZnO}$ interface, which is induced by the strong surface plasmon absorption of $\mathrm{Ag}$ particles [27, 40]. Among all the samples, $10.03 \mathrm{wt} \%$ $\mathrm{Ag} / \mathrm{ZnO}$ shows the lowest intensity of PL, indicating the highest separation efficiency of photogenerated electronhole pairs. The photocatalytic activity of the $\mathrm{Ag} / \mathrm{ZnO}$ composites will be improved if the separation efficiency of photogenerated electron-hole pairs in the $\mathrm{Ag} / \mathrm{ZnO}$ composites is higher.

\section{Catalytic Performance}

The photocatalytic performances of the hierarchical $\mathrm{ZnO}$ microspheres and $\mathrm{Ag} / \mathrm{ZnO}$ were evaluated by photodegrading MB solution, which is a typical organic pollutant from the textile industry. Under UV irradiation, the photocatalytic results of MB in the presence of different

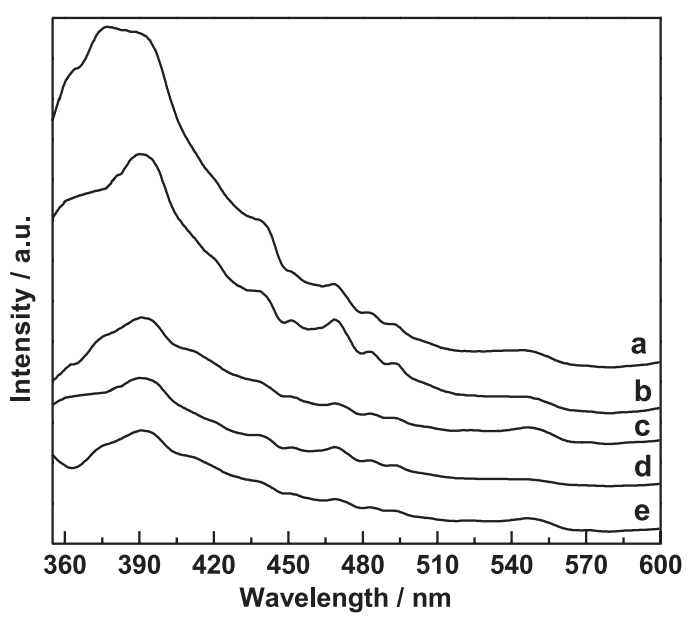

Fig. 6. PL spectra of a) $\mathrm{ZnO}$, b) $5.41 \mathrm{wt} \% \mathrm{Ag} / \mathrm{ZnO}$, c) $7.95 \mathrm{wt} \%$ $\mathrm{Ag} / \mathrm{ZnO}$, d) $10.03 \mathrm{wt} \% \mathrm{Ag} / \mathrm{ZnO}$, and e) $11.37 \mathrm{wt} \% \mathrm{Ag} / \mathrm{ZnO}$. 
catalysts (as-prepared $\mathrm{ZnO}$ and $\mathrm{Ag} / \mathrm{ZnO}$ composites) are all exhibited in Fig. 7a. In the absence of the catalyst, the degradation rate of MB under UV irradiation is extremely slow and thus photolysis can be ignored. Pure $\mathrm{ZnO}$ microspheres only display a moderate activity. However, the addition of $\mathrm{Ag}$ effectively enhances the photocatalytic performance. After exposure to UV light for $20 \mathrm{~min}$, the degradation efficiencies of $\mathrm{MB}$ are as follows: $78.8 \%$ for pure $\mathrm{ZnO}, 90.2 \%$ for $5.41 \mathrm{wt} \% \mathrm{Ag} / \mathrm{ZnO}, 94.2 \%$ for $7.95 \mathrm{wt} \% \mathrm{Ag} / \mathrm{ZnO}, 99.2 \%$ for $10.03 \mathrm{wt} \% \mathrm{Ag} / \mathrm{ZnO}$, and $96.0 \%$ for $11.37 \mathrm{wt} \% \mathrm{Ag} / \mathrm{ZnO}$. It is obvious that all $\mathrm{Ag} /$ $\mathrm{ZnO}$ composites show superior activity over pure $\mathrm{ZnO}$ and the activity of $\mathrm{Ag} / \mathrm{ZnO}$ samples firstly increase and then decrease with the increase of $\mathrm{Ag}$ content in the composites. The $10.03 \mathrm{wt} \% \mathrm{Ag} / \mathrm{ZnO}$ composite possesses the best performance, which is in accordance with the PL results.

The photodegradation of MB can be described as a pseudo-first-order reaction [41], for which the kinetic reaction can be expressed as $\ln \left(\mathrm{C}_{0} / \mathrm{C}\right)=\mathrm{kt}$, where $\mathrm{C}_{0}$ is the initial $\mathrm{MB}$ concentration, $\mathrm{C}$ is the residual $\mathrm{MB}$ concentration at different illumination intervals, $\mathrm{k}$ is the pseudo-first-rate kinetic constant $\left(\mathrm{min}^{-1}\right)$, and t represents the irradiation time. The kinetic constant $\mathrm{k}$ under UV irradiation conditions and the square of correlation coefficient of kinetic linear fitting are listed in Table 2. From the results, it is clear that $\mathrm{k}$ value for all the $\mathrm{Ag} / \mathrm{ZnO}$ composites is higher than that for pure $\mathrm{ZnO}$ microspheres. The $10.03 \mathrm{wt} \% \mathrm{Ag} / \mathrm{ZnO}$ sample achieves the optimal photocatalytic performance and the $\mathrm{k}$ value of $10.03 \mathrm{wt} \%$ $\mathrm{Ag} / \mathrm{ZnO}$ sample is two times higher than that of pure $\mathrm{ZnO}$ microspheres. These results confirm that the catalytic performance of $\mathrm{ZnO}$ is enhanced by the modification of Ag-NPs.

Fig. 7 (c, d) exhibit the catalytic performance and the kinetics of the pure $\mathrm{ZnO}$ microspheres and $\mathrm{Ag} / \mathrm{ZnO}$ composites for degradation of MB under visible light irradiation. The obtained $\mathrm{k}$ values and the square values of correlation coefficient for various catalysts are present in Table 2. In the entire irradiation process, less than $3 \%$ of $\mathrm{MB}$ is degraded without any photocatalysts. The 10.03 $\mathrm{wt} \% \mathrm{Ag} / \mathrm{ZnO}$ sample shows the most superior activity, of which $\mathrm{k}$ value is much higher than that of pure $\mathrm{ZnO}$ microspheres. With the increase of $\mathrm{Ag}$ content (from 5.41 to $10.03 \mathrm{wt} \%$ ), the photocatalytic performance and $\mathrm{k}$ value have also been increased. Nevertheless, the catalytic efficiency and $\mathrm{k}$ value decline when Ag content is further increased $(11.37 \mathrm{wt} \%)$. This result is similar a)

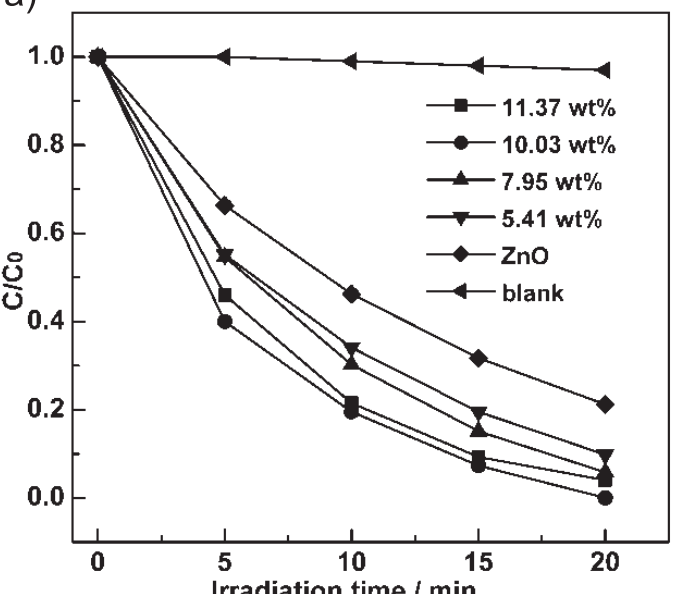

C)

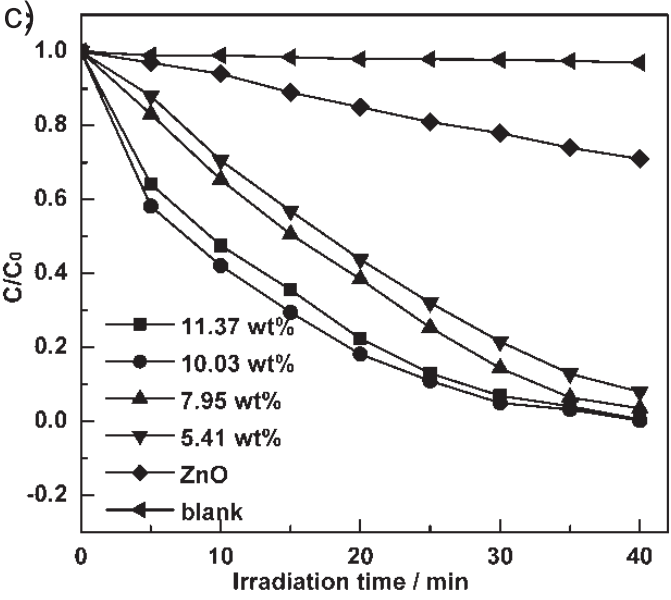

b)
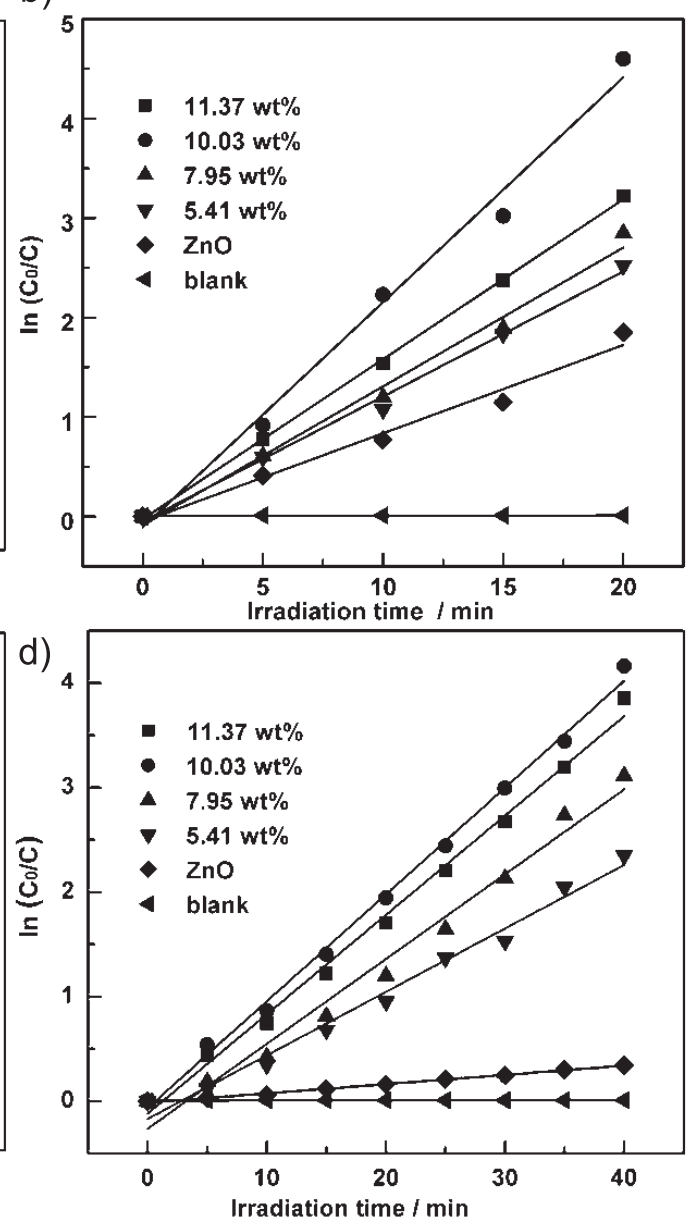

Fig. 7. a), c) Photocatalytic activity and b), d) kinetics of the obtained $\mathrm{ZnO}$ microspheres and $\mathrm{Ag} / \mathrm{ZnO}$ composites prepared with various Ag contents for degradation of MB under a), b) UV, and c), d) visible light. 
Table 2. Reaction rate constant (k) for photocatalytic degradation of MB under UV and visible light irradiation.

\begin{tabular}{|c|c|c|c|c|c|c|}
\hline \multirow{2}{*}{ Irradiation } & Constant & $\mathrm{ZnO}$ & $\begin{array}{c}5.41 \mathrm{wt} \% \\
\mathrm{Ag} / \mathrm{ZnO}\end{array}$ & $\begin{array}{c}7.95 \mathrm{wt} \% \\
\mathrm{Ag} / \mathrm{ZnO}\end{array}$ & $\begin{array}{c}10.03 \mathrm{wt} \% \\
\mathrm{Ag} / \mathrm{ZnO}\end{array}$ & $\begin{array}{c}11.37 \mathrm{wt} \% \\
\mathrm{Ag} / \mathrm{ZnO}\end{array}$ \\
\hline \multirow{3}{*}{ UV light } & $\mathrm{k} / \mathrm{min}^{-1}$ & 0.0888 & 0.1257 & 0.1396 & 0.2261 & 0.1607 \\
\cline { 2 - 7 } & $\mathrm{R}^{2 \mathrm{a}}$ & 0.9899 & 0.9921 & 0.9854 & 0.9563 & 0.9992 \\
\hline \multirow{2}{*}{ Visible light } & $\mathrm{k} / \mathrm{min}^{-1}$ & 0.0088 & 0.0607 & 0.0830 & 0.1022 & 0.0950 \\
\cline { 2 - 7 } & $\mathrm{R}^{2 \mathrm{a}}$ & 0.9904 & 0.9836 & 0.9886 & 0.9961 & 0.9934 \\
\hline
\end{tabular}

${ }^{a} R^{2}$ : the square of correlation coefficient of kinetic linear fitting.

to the activity investigated under UV irradiation. When $\mathrm{Ag}$ is incorporated into $\mathrm{ZnO}$, two different phenomena would occur. For Ag content $\leq 10.03 \mathrm{wt} \%$, Ag particles loaded on $\mathrm{ZnO}$ might act as an electron accepter and the electrons on the surface of $\mathrm{ZnO}$ could effectively transfer to Ag particles. In contrast, at higher Ag content, some Ag particles might reversibly act as the recombination centers of electrons and holes and thus reduce the photocatalytic efficiency of the catalyst. Similar results are also observed in the literature $[20,40]$.

For the purpose of the application, it is crucial for the photocatalyst to maintain superior photocatalytic activity and stability over a long period of time. As Fig. 8 illustrates, the $10.03 \mathrm{wt} \% \mathrm{Ag} / \mathrm{ZnO}$ sample exhibits effective photocatalytic performance under $\mathrm{UV}$ and visible light irradiation. There is insignificant loss of the photocatalytic efficiency after four cycles, indicating the highly stable and reusable of the $10.03 \mathrm{wt} \% \mathrm{Ag} / \mathrm{ZnO}$ sample. The SEM images of the used $10.03 \mathrm{wt} \% \mathrm{Ag} / \mathrm{ZnO}$ sample present that this sample still maintains the original structure even after several recycles. The possible reason for the favorable photocatalyst is that the hierarchical microspheres have an overall dimension in micrometers with nanosized units that are stabilized to ensure superior structural stability $[36,42]$.

\section{Photocatalytic Mechanism}

On the basis of the aforementioned results and the theory analysis [16], a proposed mechanism diagram a)
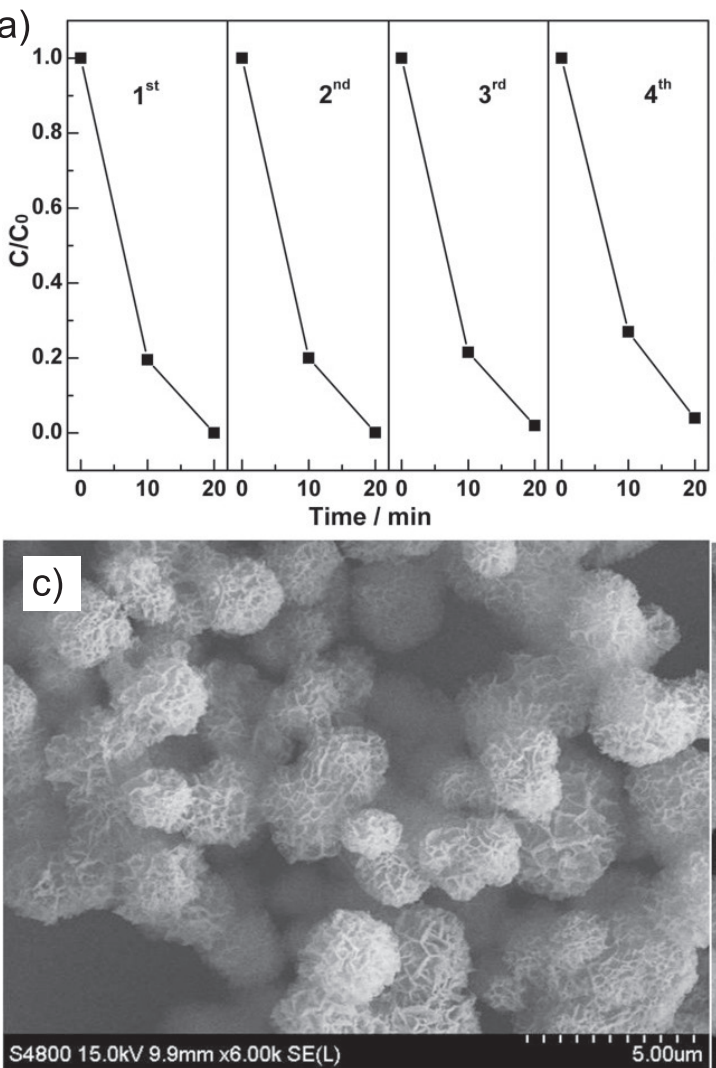

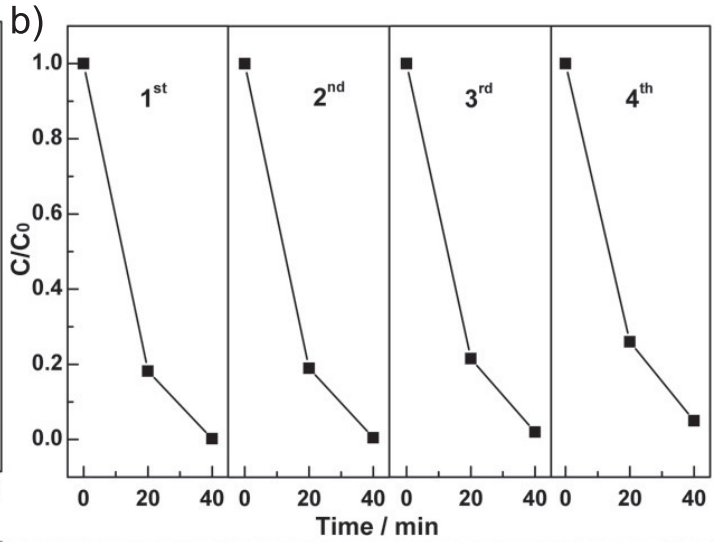

d)
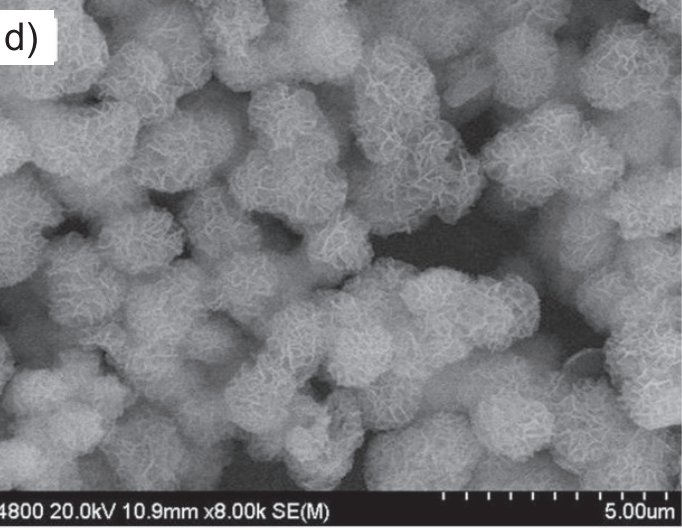

Fig. 8. Recycle degradation of MB performance of $10.03 \mathrm{wt} \% \mathrm{Ag} / \mathrm{ZnO}$ sample under a) UV and b) visible light irradiation and the SEM images of the $10.03 \mathrm{wt} \% \mathrm{Ag} / \mathrm{ZnO}$ sample that had been reused after four cycles under c) UV and d) visible light irradiation. 

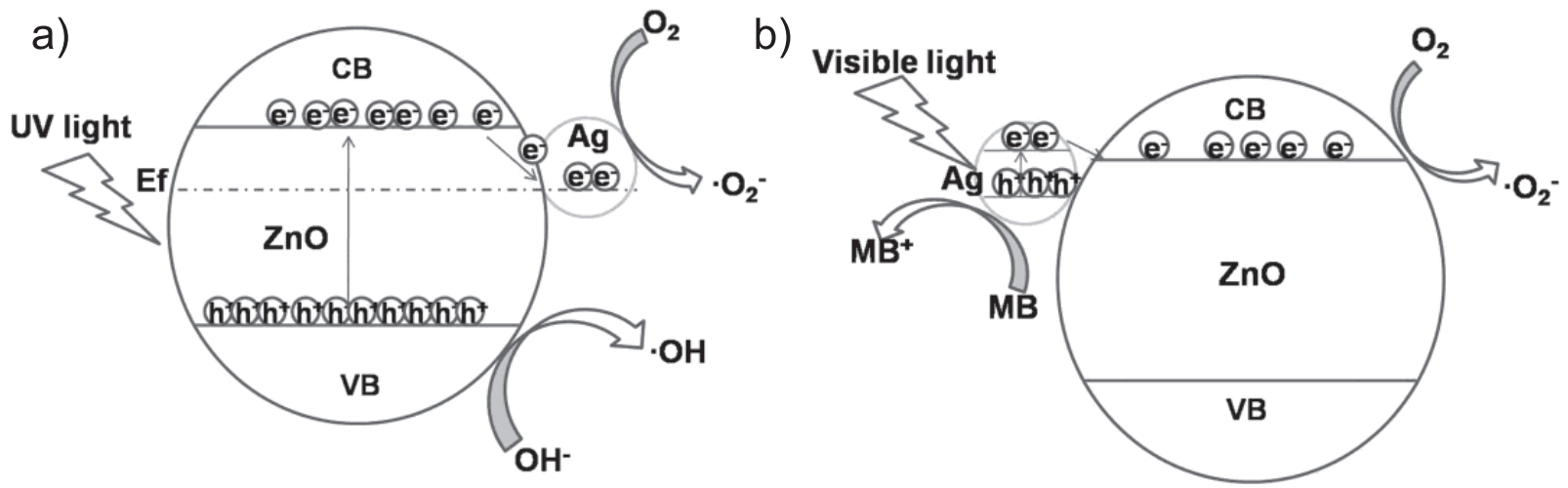

Fig. 9. Schematic diagram of photocatalytic mechanism $\mathrm{Ag} / \mathrm{ZnO}$ composites under $\mathrm{UV}$ a) and visible light b) irradiation.

of the enhanced photocatalytic performance of the $\mathrm{Ag} / \mathrm{ZnO}$ composites under $\mathrm{UV}$ and visible light irradiation is illustrated schematically in Fig. 9.

The improved photocatalytic efficiency of the $\mathrm{Ag} / \mathrm{ZnO}$ heterostructure under UV irradiation can be mainly ascribed to the formation of the Schottky barriers at metal-semiconductor interface between $\mathrm{Ag}$ particles and hierarchical $\mathrm{ZnO}$ microspheres, which are propitious to the segregation of charges and inhibited the charge recombination. When $\mathrm{Ag} / \mathrm{ZnO}$ composites are illuminated by UV light with photo energy equal to or higher than the band gap of $\mathrm{ZnO}$, the $\mathrm{ZnO}$ microspheres could be simultaneously excited to form electron-hole pairs. As shown in Fig. 9a, the photogenerated electron in the CB of $\mathrm{ZnO}$ could migrate to $\mathrm{Ag}$ particles due to the driving force produced by the deflexed energy band in the space charge region. Ag particles, acting as electron sinks, not only reduce the recombination ratio of electron-hole pairs but also increase the lifetime of the photogenerated pairs. Then the absorbed $\mathrm{O}_{2}$ and $\mathrm{H}_{2} \mathrm{O}$ on the surface of the $\mathrm{Ag} / \mathrm{ZnO}$ composites would react with the photogenerated electrons to form superoxide radical anions such as $\cdot \mathrm{O}_{2}-, \cdot \mathrm{HO}_{2}$, and $\cdot \mathrm{OH}$. The photoinduced holes are inclined to interact with $\mathrm{OH}^{-}$or $\mathrm{H}_{2} \mathrm{O}$ to further generate $\cdot \mathrm{OH}$ species, which has a strong oxidizability to decompose most of the pollutants [43-44].

The photocatalytic process under visible light irradiation for the $\mathrm{Ag} / \mathrm{ZnO}$ composites can be interpreted by the proposed mechanism shown in Fig. 9b. When the $\mathrm{Ag} / \mathrm{ZnO}$ composites are exposed to visible light, $\mathrm{Ag}$ particles would capture the photons due to the strong SPR effect, which results in the formation of electron-hole pairs in the Ag particles. Subsequently, the photoinduced electrons transfer from $\mathrm{Ag}$ to the $\mathrm{CB}$ of $\mathrm{ZnO}$ and then these injected electrons are consumed by the $\mathrm{O}_{2}$ dissolved in the solution to yield various reactive oxidative species [16, 45]. Photodegradation of MB could subsequently take place through the attack of reactive oxidative species.

On the basis of the above-mentioned results, it is obvious that the optimal $\mathrm{Ag}$ content for preparing $\mathrm{Ag} / \mathrm{ZnO}$ composites with a superior catalytic performance is about $10.03 \mathrm{wt} \%$, which can effectively hinder the recombination of photoinduced electron-hole pairs to achieve the best photocatalytic performance. Besides, from Figs 6 and 7 it is clear that the order of PL intensities of the samples is just opposite that of the photocatalytic performance, confirming the occurrence of the separation effect between the photogenerated electrons and holes.

\section{Conclusions}

Hierarchical $\mathrm{Ag} / \mathrm{ZnO}$ microspheres with different Ag content were successfully synthesized via a facile two-step method. The as-prepared $\mathrm{Ag} / \mathrm{ZnO}$ composites exhibited superior photocatalytic activity over pure $\mathrm{ZnO}$ microspheres on the degradation of MB under UV or visible light irradiation. After being used four times, more than $90 \%$ of degradation efficiency could also be maintained. The characterization results showed that the enhanced photocatalytic performance and high photostability could be ascribed to the incorporation of $\mathrm{Ag}$ nanoparticles and the unique hierarchical structure. The Ag nanoparticles located on the surface of the $\mathrm{ZnO}$ microspheres acted as electron sinks to improve the charge separation and extend the light-absorption range through surface plasmon resonance effect.

\section{Acknowledgements}

This work was supported by the National Basic Research Program of China (2013CB933102) and Natural Science Project of Xiamen Medical College (K2016-15).

\section{References}

1. XU F., YUAN Y., HAN H., WU D., GAO Z., JIANG K. Synthesis of $\mathrm{ZnO} / \mathrm{CdS}$ hierarchical heterostructure with enhanced photocatalytic efficiency under nature sunlight. Crystengcomm, 14, 3615, 2012.

2. HAN Z., REN L., CUI Z., CHEN C., PAN H., CHEN J. $\mathrm{Ag} / \mathrm{ZnO}$ flower heterostructures as a visible-light driven photocatalyst via surface plasmon resonance. Applied Catalysis B: Environmental. 126, 298, 2012. 
3. ZHANG H., CHEN G., BAHNEMANN D.W. Photoelectrocatalytic materials for environmental applications, Journal of Materials Chemistry. 19, 5089, 2009.

4. KAYACI F., VEMPATI S., DONMEZ I., BIYIKLI N., UYAR T. Role of zinc interstitials and oxygen vacancies of $\mathrm{ZnO}$ in photocatalysis: a bottom-up approach to control defect density. Nanoscale, 6, 10224, 2014.

5. BEGUM G., MANNA J., RANA R.K. Controlled Orientation in a Bio-Inspired Assembly of $\mathrm{Ag} / \mathrm{AgCl} / \mathrm{ZnO}$ Nanostructures Enables Enhancement in Visible-LightInduced Photocatalytic Performance. Chemistry-A European Journal, 18, 6847, 2012.

6. LIU Y., WEI S., WEI G. Ag/ZnO heterostructures and their photocatalytic activity under visible light: Effect of reducing medium. Journal of Hazardous Materials, 287, 59, 2015.

7. LI Y., ZHOU X., HU X., ZHAO X., FANG P. Formation of Surface Complex Leading to Efficient Visible Photocatalytic Activity and Improvement of Photostabilty of $\mathrm{ZnO}$. Journal of Physical Chemistry C, 113, 16188, 2009.

8. JIN J.J., YU J.G., GUO D.P., CUI C., HO W.K. A Hierarchical Z-Scheme CdS- $\mathrm{WO}_{3}$ photocatalyst with Enhanced $\mathrm{CO}_{2}$ reduction Activity. Small, 11, 5262, 2015.

9. LI J.D., YU C.L., FANG W., ZHU L.H., ZHOU W.Q., FAN Q.Z., Preparation, characterization and photocatalytic performance of heterostructured $\mathrm{AgCl} / \mathrm{Bi}_{2} \mathrm{WO}_{6}$ microspheres. Chinese Journal of Catalysis, 36, 987, 2015.

10. KAYACI F., VEMPATI S., OZGIT-AKGUN C., DONMEZ I., BIYIKLI N., UYAR T. Selective isolation of the electron or hole in photocatalysis: $\mathrm{ZnO}^{-} \mathrm{TiO}_{2}$ and $\mathrm{TiO}_{2}-\mathrm{ZnO}$ core-shell structured heterojunction nanofibers via electrospinning and atomic layer deposition. Nanoscale, 6, 5735, 2014.

11. KADAM A., DHABBE R., GOPHANE A., SATHE T., GARADKAR K., Template free synthesis of $\mathrm{ZnO} / \mathrm{Ag}_{2} \mathrm{O}$ nanocomposites as a highly efficient visible active photocatalyst for detoxification of methyl orange. Journal of Photochemistry \& Photobiology, B: Biology, 154, 24, 2016

12. LIU G., LI G., QIU X., LI L. Synthesis of $\mathrm{ZnO} /$ titanate nanocomposites with highly photocatalytic activity under visible light irradiation. Journal of Alloys \& Compounds, 481, 492, 2009.

13. QIU R., ZHANG D., MO Y., LIN S., BREWER E., HUANG X., XIONG Y., Photocatalytic activity of polymer-modified $\mathrm{ZnO}$ under visible light irradiation. Journal of Hazardous Materials, 156, 80, 2008.

14. SUN Y.Q., SUN Y., ZHANG T., CHEN G., ZHANG F., LIU D., CAI W., LI Y., YANG X., LI C. Complete Au@ $\mathrm{ZnO}$ Core-Shell Nanoparticles with Enhanced Plasmonic Absorption Enabling Significantly Improved Photocatalysis. Nanoscale, 8, 10774, 2016.

15. Yu C.L., BAI Y., CHEN J.C., ZHOU W.Q., HE H.B., YU J.C., ZHU L.H., XUE S.S. Pt/Bi $\mathrm{WO}_{6}$ composite microflowers: High visible light photocatalytic performance and easy recycle. Separation and Purification Technology, 154, 115, 2015.

16. KURIAKOSE S., CHOUDHARY V., SATPATI B., MOHAPATRA S. Facile synthesis of Ag-ZnO hybrid nanospindles for highly efficient photocatalytic degradation of methyl orange. Physical Chemistry Chemical Physics, 16, 17560, 2014.

17. YU C.L., YANG K., XIE Y., FAN Q.Z., YU J.C., SHU Q., WANG C.Y. Novel hollow Pt-ZnO nanocomposite microspheres with hierarchical structure and enhanced photocatalytic activity and stability. Nanoscale, 5, 2142, 2013.

18. DAS S., SINHA S., SUAR M., YUN S., MISHRA A., TRIPATHY S. K. Solar-photocatalytic disinfection of Vibria cholerae by using $\mathrm{Ag} @ \mathrm{ZnO}$ core-shell structure nanocomposites. Journal of Photochemistry Photobiology B: Biology, 142, 68, 2015.

19. PENG L., ZHE W., TONG W., QING P., YADONG L. $\mathrm{Au}-\mathrm{ZnO}$ hybrid nanopyramids and their photocatalytic properties. The Journal of the American Chemical Society, 133, 5660, 2011.

20. LIU H.R., SHAO G.X., ZHAO J.F., ZHANG Z.X., ZHANG Y., LIANG J., LIU X.G., JIA H.S., XU B.S. Worm-Like Ag/ ZnO Core-Shell Heterostructural Composites: Fabrication, Characterization, and Photocatalysis, The Journal of Physical Chemistry. C, 116, 16182, 2012.

21. LU F., CAI W., ZHANG Y. ZnO Hierarchical Micro/ Nanoarchitectures: Solvothermal Synthesis and Structurally Enhanced Photocatalytic Performance \&dagger. Advanced Functional Materials, 18, 1047, 2008.

22. YU C.L., ZHOU W.Q., LIU H., LIU Y., DINGYSUOU D.D. Design and fabrication of microsphere photocatalysts for environmental purification and energy conversion. Chemical Engineering Journal, 287, 117, 2016.

23. YU C.L., CAO F.F., LI X., LI G., XIE Y., YU J.C., SHU Q., FAN Q.Z., CHEN J.C. Hydrothermal synthesis and characterization of novel PbWO4 microspheres with hierarchical nanostructures and enhanced photocatalytic performance in dye degradation. Chemical Engineering Journal, 219, 86, 2013.

24. FANG W., YU C.L. Thermostability and photocatalytic performance of $\mathrm{BiOCl}_{05} \mathrm{Br} 0.5$ composite microspheres. Journal of Materials Research, 30, 3125, 2015.

25. JING W.X., QI H., SHI J.F. JIANG Z.D., ZHOU F., CHENG Y.Y., GAO K. Effects of the geometries of microscale substrates on the surface morphologies of $\mathrm{ZnO}$ nanorod-based hierarchical structures. Applied Surface Science, 355, 403, 2015.

26. SARAVANAN R., KARTHIKEYAN N., GUPTA V.K., THIRUMAL E., THANGADURAI P., NARAYANAN V., STEPHEN A., $\mathrm{ZnO} / \mathrm{Ag}$ nanocomposite: An efficient catalyst for degradation studies of textile effluents under visible light. Materials Science Engineering: C, 33, 2235, 2013.

27. LIN D., WU H., ZHANG R., PAN W. Enhanced Photocatalysis of Electrospun Ag-ZnO Heterostructured Nanofibers. Chemistry of Materials, 21, 3479, 2009.

28. ALAMMAR T., MUDRING A.V. Facile preparation of Ag/ $\mathrm{ZnO}$ nanoparticles via photoreduction. Journal of Materials Science, 44, 3218, 2009.

29. ZHU G., LIU Y., XU H., CHEN Y., SHEN X., XU Z. Photochemical deposition of Ag nanocrystals on hierarchical $\mathrm{ZnO}$ microspheres and their enhanced gas-sensing properties. Crystengcomm, 14, 719, 2011.

30. MOSQUERA E., ROJAS-MICHEA C., MOREL M., GRACIA F., FUENZALIDA V., ZARATE R.A. Zinc oxide nanoparticles with incorporated silver: Structural, morphological, optical and vibrational properties. Applied Surface Science, 347, 561, 2015.

31. LIU T.Z., LI Y.Y., ZHANG H., WANG M., FEI X.Y., DUO S.W., CHEN Y., PAN J., WANG W. Tartaric acid assisted hydrothermal synthesis of different flower-like $\mathrm{ZnO}$ hierarchical architectures with tunable optical and oxygen vacancy-induced photocatalytic properties. Applied Surface Science, 357, 516, 2015.

32. TRIPATHY N., AHMAD R., KUK H., LEE D.H., HAHN Y.B., KHANG G. Rapid methyl orange degradation using 
porous $\mathrm{ZnO}$ spheres photocatalyst. Journal of Photochemistry \& Photobiology, B: Biology, 161, 312, 2016.

33. TANG D.M., LIU G., LI F., TAN J., LIU C., LU G.Q., CHENG H.M. Synthesis and Photoelectrochemical Property of Urchin-like $\mathrm{Zn} / \mathrm{ZnO}$ Core-Shell Structures. The Journal of Physical Chemistry C, 113, 11035, 2009.

34. MOUDLER J.F., STICKLE W.F., SOBOL P.E., BOMBEN K.D. Handbook of X-ray Photoelectron Spectroscopy, Perkin-Elmer, Minnesota, 1992.

35. DENG Q., TANG H.B., LIU G., SONG X.P., XU G.P., LI Q., NG D.H.L., WANG G.Z. The fabrication and photocatalytic performances of flower-like Ag nanoparticles/ $\mathrm{ZnO}$ nanosheets-assembled microspheres. Applied Surface Science, 331, 50, 2015.

36. DENG Q., DUAN X., NG D.H.L., TANG H., YANG Y., KONG M., WU Z., CAI W., WANG G., Ag Nanoparticle Decorated Nanoporous ZnO Microrods and Their Enhanced Photocatalytic Activities, ACS Applied Materials \& Interfaces. 4, 6030, 2012.

37. HUANG Q.L., ZHANG Q.T., YUAN S.S., ZHANG Y.C., ZHANG M. One-pot facile synthesis of branched $\mathrm{Ag}-\mathrm{ZnO}$ heterojunction nanostructure as highly efficient photocatalytic catalyst. Applied Surface Science, 353, 949, 2015.

38. WU A.P., TIAN C.G., YAN H.J., HONG Y., JIANG B.J., FU H.G. Intermittent microwave heating-promoted rapid fabrication of sheet-like Ag assemblies and small-sized Ag particles and their use as co-catalyst of $\mathrm{ZnO}$ for enhanced photocatalysis. Journal of Materials Chemistry A, 2, 3015, 2014.
39. LIU H., HU Y., ZHANG Z., LIU X., JIA H., XU B. Synthesis of spherical $\mathrm{Ag} / \mathrm{ZnO}$ heterostructural composites with excellent photocatalytic activity under visible light and UV irradiation, Appl. Surf. Sci., 355, 644, 2015.

40. LIANG Y., GUO N., LI L., LI R., JI G., GAN S. Fabrication of porous $3 \mathrm{D}$ flower-like $\mathrm{Ag} / \mathrm{ZnO}$ heterostructure composites with enhanced photocatalytic performance. Applied Surface Science, 332, 32, 2015.

41. LAI Y., MING M., YU Y. One-step synthesis, characterizations and mechanistic study of nanosheetsconstructed fluffy $\mathrm{ZnO}$ and $\mathrm{Ag} / \mathrm{ZnO}$ spheres used for Rhodamine B photodegradation. Applied Catalysis B-Environmental., 100, 491, 2010.

42. LI J., WANG G., WANG H., TANG C., WANG Y., LIANG C., CAI W., ZHANG L. In situ self-assembly synthesis and photocatalytic performance of hierarchical $\mathrm{B}_{\mathrm{i} 0.5} \mathrm{Na}_{0.5} \mathrm{TiO}_{3}$ micro/nanostructures. Journal of Materials Chemistry, 15, 2253, 2009.

43. FAGERIA P., GANGOPADHYAY S., PANDE S. Synthesis of $\mathrm{ZnO} / \mathrm{Au}$ and $\mathrm{ZnO} / \mathrm{Ag}$ nano-particles and their photocatalytic application using UV and visible light. Rsc Advances, 4, 24962, 2014.

44. WANG S., YU Y., ZUO Y., LI C., YANG J., LU C. Synthesis and photocatalysis of hierarchical heteroassemblies of $\mathrm{ZnO}$ branched nanorod arrays on $\mathrm{Ag}$ core nanowires. Nanoscale, 4, 5895, 2012.

45. BOUZID H., FAISAL M., HARRAZ F.A., AL-SAYARI S.A., ISMAIL A.A. Synthesis of mesoporous $\mathrm{Ag} / \mathrm{ZnO}$ nanocrystals with enhanced photocatalytic activity, Catalysis Today, 252, 20, 2015. 